\title{
Congenital oesophageal achalasia in the dog
}

\author{
R ICHA R D J. EARLAM, PAUL E. ZOLLMA N, AND \\ F. HENRY ELLIS, JR.
}

\begin{abstract}
From the Mayo Graduate School of Medicine (University of Minnesota), and the Sections of Veterinary Medicine and Surgery, Mayo Clinic and Mayo Foundation, Rochester, Minnesota, U.S.A.
\end{abstract}

A 3-month-old German shepherd puppy with a congenitally dilated oesophagus had radiographic, cinefluoroscopic, and oesophageal motility studies before a modified Heller operation was performed. Subsequent examination of the oesophagus revealed no ganglion cells, and the condition was considered to be identical with human achalasia. In dogs, this appears to be more common in the German shepherd breed.

In achalasia of the oesophagus the body of the oesophagus lacks peristalsis, and is usually dilated while the lower sphincter fails to respond normally to swallowing. Pressure records from the oesophagus rarely show an increase in the resting pressure of the lower sphincter. The term 'cardiospasm', which implies increased pressure, is not so acceptable as achalasia, which describes a failure of the sphincter to relax and contract in a co-ordinated manner. This inco-ordination is related to loss of the enteric neurons or ganglion cells in Auerbach's myenteric plexus. The absence or reduction in number of these nerve cells is a common finding in this disease and occurs mainly in the body of the oesophagus, but may affect the lower sphincter and the body in varying proportions. The aetiology of the loss of enteric neurons is unknown. For this reason it is desirable to accumulate as much information about the epidemiology of the disease as possible in the hope that a common aetiological factor may emerge. Dogs with an enlarged oesophagus have been described before, but this is the first occasion on which cinefluoroscopy, oesophageal pressure studies, and histological examination have been performed in sufficient detail for it to be said that achalasia of the oesophagus definitely can occur in dogs. A German shepherd dog (the term used in North America to describe an Alsatian) with achalasia is presented, and 43 other cases described in the literature are discussed.

\section{CASE REPORT}

A German shepherd puppy, 3 months old, was studied because she failed to eat a normal diet and after each meal vomited undigested a large bolus of food. She $\frac{3}{3}$ was one of a litter of seven and differed in no way from her littermates until weaned, after which she $\vec{\bullet}$ did not gain weight satisfactorily and, when first seen, $\stackrel{\mathscr{D}}{y}$ weighed $8.4 \mathrm{~kg}$. Both the sire and the dam were: normal and had previously had normal litters.

Fluoroscopy showed a grossly enlarged oesophagus (Fig. 1) with a few peristaltic contractions in the dilated region which progressed distally along the wall of the oesophagus without actually occluding $\mathbb{Q}$ the dilated chamber. During fluoroscopy, which lasted $\underset{\Rightarrow}{\Rightarrow}$ 10 minutes, the sphincter was seen to relax only three times.

Oesophageal motility studies were performed as originally described by Schlegel and Code (1958).? Four small polyethylene tubes were tied together and passed down the oesophagus. The lumen of one tube음 contained wire that prevented any acute bends. Another tube was covered at its distal end by a smallio water-filled balloon. The remaining two water-filled 3 . tubes had lateral openings at 5 and $10 \mathrm{~cm}$. proximalo to the balloon. Simultaneous pressures were recorded 3 from the balloon and the two open-tip tubes at different levels in the oesophagus. The recordings $\triangle$ revealed a few simultaneous pressure humps after $D$ swallowing in the body of the oesophagus (Fig. 2). But the sphincter, which had a normal pressure profile, N relaxed poorly and infrequently. When there wasrelaxation, it was incomplete because a premature ${ }^{\circ}$ contraction cut it short. These findings closely corre- N lated with those seen on cinefluoroscopy. They were also similar to the recordings made in humans.

A modified Heller operation was performed whenc the dog was $3 \frac{1}{2}$ months old. Under ether anaesthesia, with controlled respiration and a cuffed endotracheal ${ }^{+}$ tube, the thorax was opened through the left eighth 7 intercostal space. Patches of pneumonia were dis-웅 covered in the upper and middle lobes on this side. $\stackrel{\square}{\square}$ The oesophagus was dilated as far as it could be $\mathbb{D}$ traced under the hilum of the left lung, but there was $\bigcirc$ 


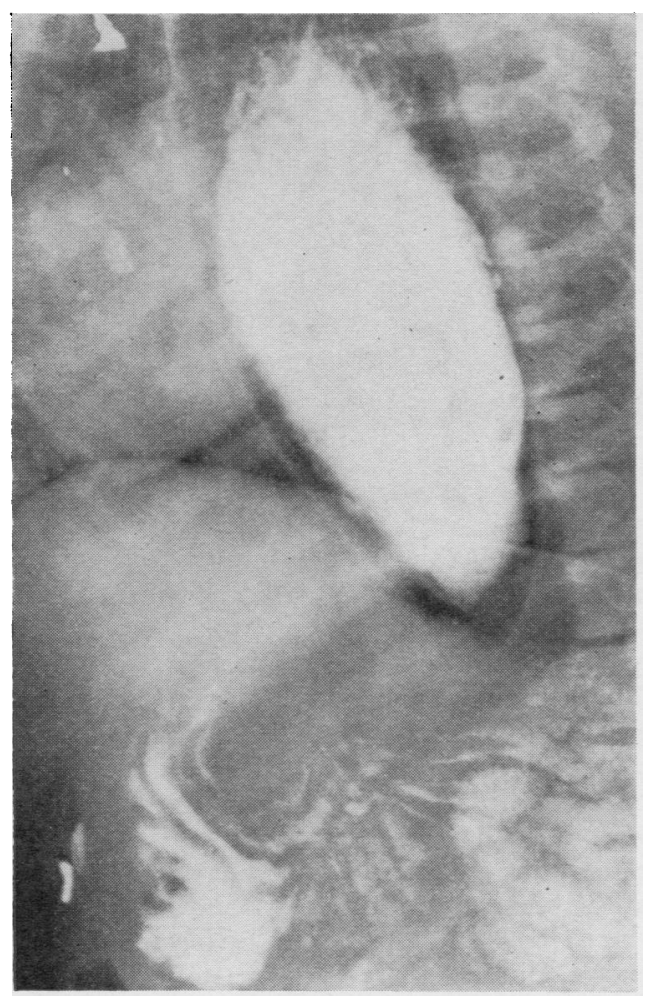

FIG. 1. Oesophageal radiograph after barium swallow shows dilated oesophagus in which barium is surrounded by non-opaque fluid. Some radiopaque material has passed into the stomach. a normal-sized portion in the region of the hiatus of the diaphragm. The lower end was mobilized without penetrating the thin mediastinum, and myotomy was performed extending from the gastro-oesophageal junction toward the dilated portion for $5 \mathrm{~cm}$., the phreno-oesophageal ligament being undisturbed. The myotomy incision was placed anterolaterally between the anterior and posterior vagi and the mucosa was separated from muscle for about half its circumference so that mucosa pouted through and prevented the muscle from uniting again across the incision.

During the next two days the puppy was fed in the upright position with a mixture of milk and water. Whereas formerly the fluid did not pass into the stomach, it was now heard to gurgle into the stomach after swallowing. However, on the third postoperative day the dog succumbed with a respiratory infection which could not be controlled with antibiotics.

Necropsy confirmed that the immediate cause of death was a pulmonary infection affecting the whole of both lungs except the left lower lobe. The cause of this was not determined, but distemper was excluded because the puppy had been inoculated and no inclusion bodies were discovered in histological sections of the lung. The infection could have been secondary to aspiration of food and was exacerbated by the anaesthesia.

The oesophagus (Fig. 3) was thin and dilated throughout its whole length, and, when filled with water, the water passed readily through the lower sphincter from both directions, thus excluding a stricture. The oesophagus was $27 \mathrm{~cm}$. long, its maximal circumference was $13.5 \mathrm{~cm}$., and the muscle coat was approximately $1.5 \mathrm{~mm}$. thick. The nerve supply and the arterial blood supply were macro-

Lower

Mid
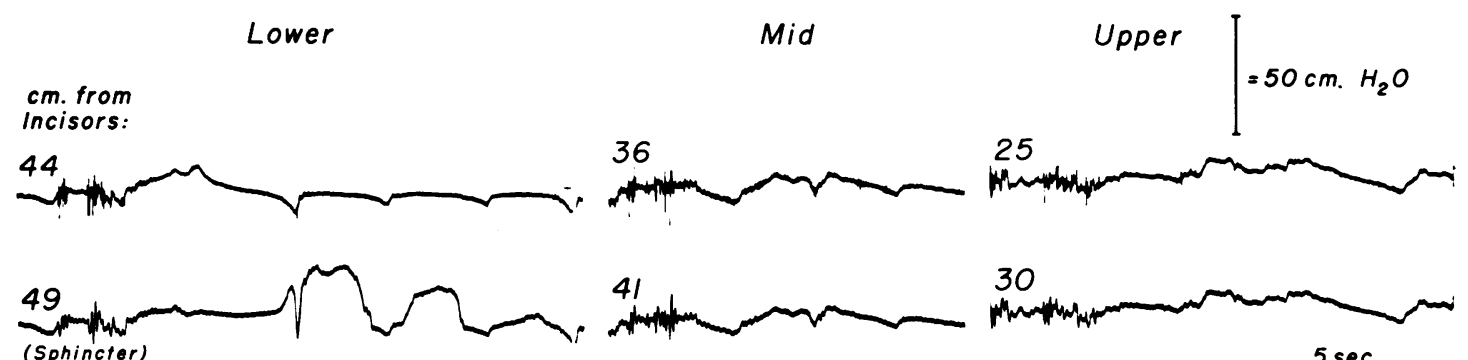

30

cm. from

Incisors:

44

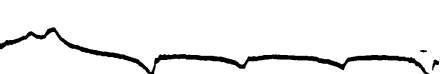

25
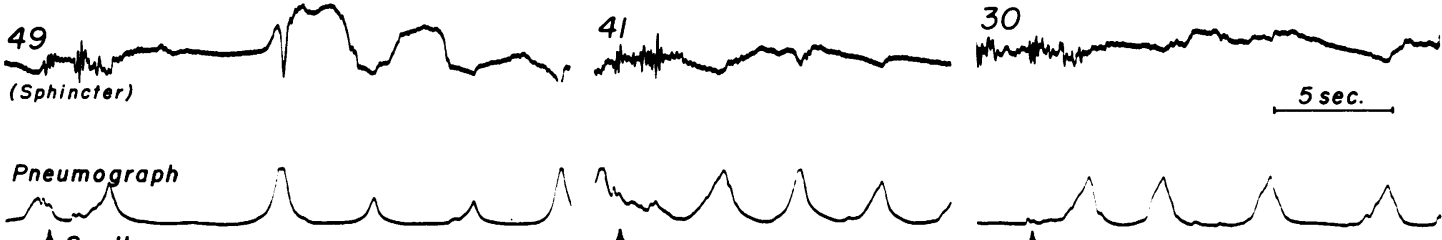

A Swallow
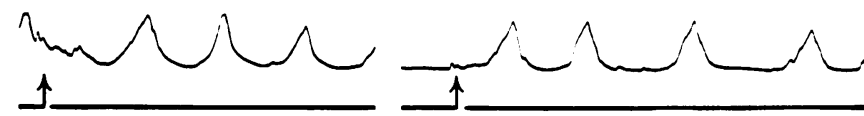

FIG. 2. Tracings of intraluminal pressures in the lower, middle, and upper parts of the oesophagus showing feeble contractions and lack of peristalsis in the body of the oesophagus and weak contraction at the sphincter. 


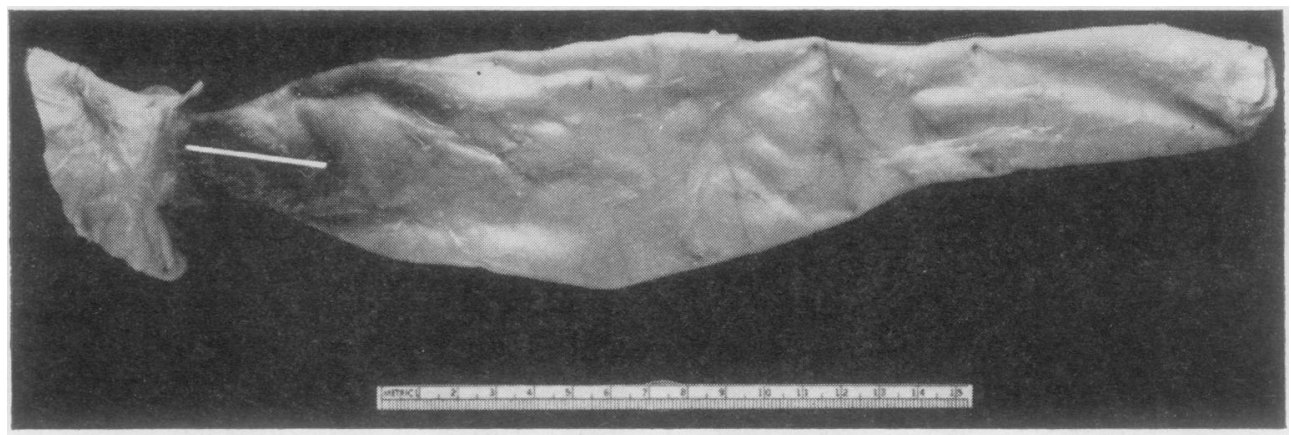

FIG. 3. Necropsy specimen of oesophagus showing collapsed thin walls.

scopically normal; the salivary glands were of the usual size, and no large vascular anomaly was present.

Histological examination revealed no ganglion cells in Auerbach's plexus between the muscle layers of the oesophagus (Fig. 4) as compared with normal (Fig. 5). The stomach, small intestine, colon, and trachea all contained normal ganglion cells.

\section{DISCUSSION}

The term 'dilated oesophagus' is not sufficiently. exact to describe anything more than an enlarged oesophagus. In dogs, the condition may be due to achalasia or to a vascular ring anomaly. Strictures secondary to trauma, tumours, parasites, or foreign bodies can be differentiated, but an oesophagus enlarged from compression by an arterial ring has frequently been reported as a dilated oesophagus. If the oesophagus is constricted by a vascular ring, the obstruction is usually in the upper part, the dilatation having the appearance of a diverticulum in the upper part of the thorax, which is larger than in achalasia, while the distal part of the oesophagus and its lower sphincter are normal (Milks and Williams, 1935 ; Detweiler and Allam, 1955 ; Lawson, Penhale, and Smith, 1957).

Dilatation of the oesophagus may occur in the horse (Hutyra, Marek, and Manninger, 1938), but idiopathic hypertrophy is more common and has been described in horses, foals, and a hinny (Hayes, 1908; Joest, 1926; Nieberle and Cohrs, 1931 ; Djukič and Oreškovič, 1959 ; Wejda, 1961 ; Guarda, 1962). One of us (P. E. Z.) has seen a dilated oesophagus in a rabbit, but since the obstruction was in the mid-thoracic region this probably represented a vascular anomaly.

Forty-four cases of oesophageal dilatation in the dog have now been reported, and possible examples of a vascular anomaly have been ex- cluded in the Table. In the majority of cases there is not enough clinical or pathological information to justify their being grouped together under any other title than that of dilated oesophagus.

The hereditary and familial aspects are interesting because in dogs there are breed differences. German shepherd dogs form the largest single group. The six greyhounds described by Spy (1963) may have had a vitamin deficiency and are therefore not significant. Lacroix (1949) stated that the breeder whose Great Dane sired the puppy he described said that other offspring had had a similar condition over the past six years, but gives no further details. Brasmer (1953) describes three German shepherd dogs, of which three had the same sire and two the same dam, but the previous 12 litters had been normal. It may be relevant that the two dams had in common an international champion great-grandfather. Breshears (1965) found three, of which one is still alive, in a litter of eight German shepherd dogs. Morgan and Lumb (1964) treated a German shepherd successfully, and this dam later produced a normal litter. The present puppy had normal parents as demonstrated by oesophageal motility and fluoroscopy, and in a well-studied family tree there were no others affected.

The geographical distribution tends to suggest that this is a spontaneously occurring congenital condition rather than one caused by infection with bacteria, viruses, or parasites such as Trypanosoma cruzi, the cause of Chagas' disease, that are themselves associated with the climate. The majority are from North America, but occasional cases occur in European countries, Australia, and South Africa. It is curious that none has been described in England, France, or Alsace, the country of origin of German shepherd dogs.

The age at presentation is usually after weaning. Prior to this, the intake of food is small 


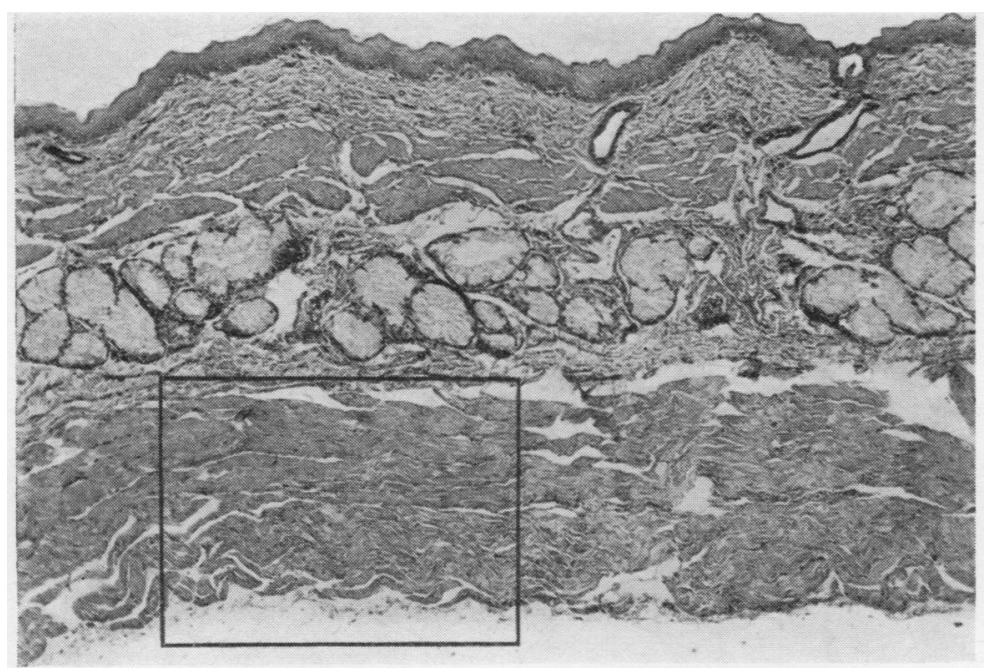

FIG. 4. (a) Section through body of oesophagus of dog with achalasia. Haematoxylin and eosin. $\times 65$.

FIG. 4. (b) Intermuscular layer shown in the area marked contained blood vessels, nerve fibres, and fibroblasts, but no ganglion cells. Haematoxylin and eosin. $\times 190$.

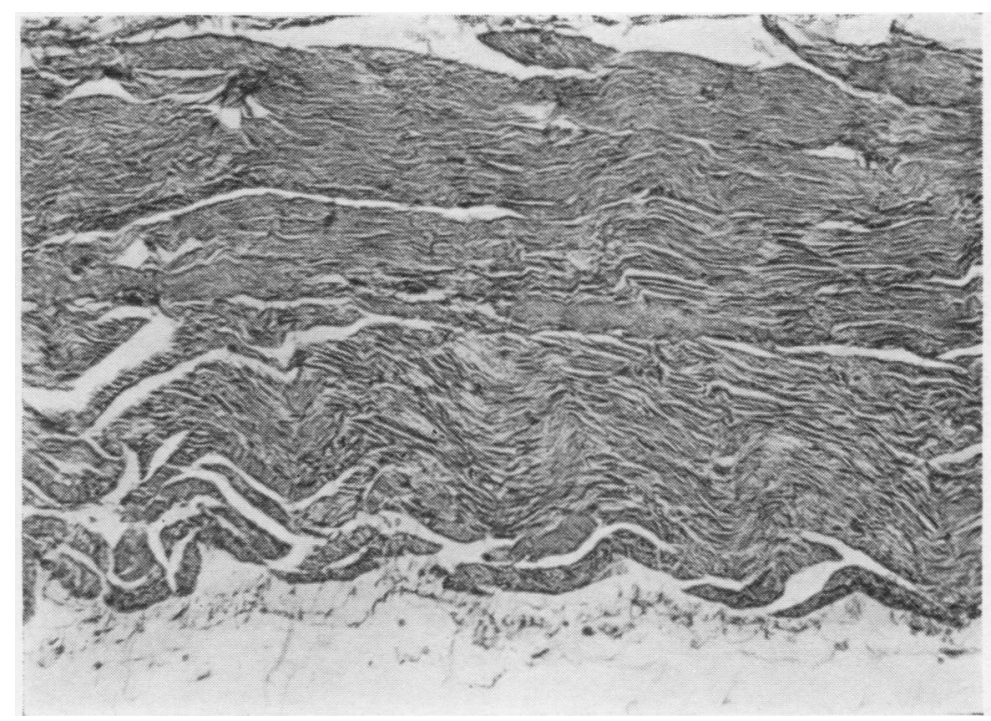

quantities of milk, and it is only with the ingestion of larger quantities of solid food that symptoms occur. The oldest dog reported as having the condition described was a German shepherd, 11 years old, on which a modified Heller operation was performed by Teunissen (1957). This appears to be a genuine case, but may possibly have been congenital because the duration of symptoms was said to be months.

Vomiting of an undigested bolus of food covered with saliva and mucus is the usual presentation. This may occur at any interval after eating ; it may depend on the activity of the dog, but usually occurs within two hours. The dog lowers its head and painlessly regurgitates without any effort. In spite of a good appetite, the animal fails to gain weight satisfactorily.

De Jong (1935) and Morgan and Lumb (1964) both described how the dilated oesophagus can be felt on the left side of the neck, and when the swelling is palpated, gurgling can be heard. This did not occur in our experience. If pressure on the stomach can induce reflux, the diagnosis of a dilated oesophagus similar to that in achalasia in the human must not be made. Oesophagoscopy has been performed on a dilated oeso- 


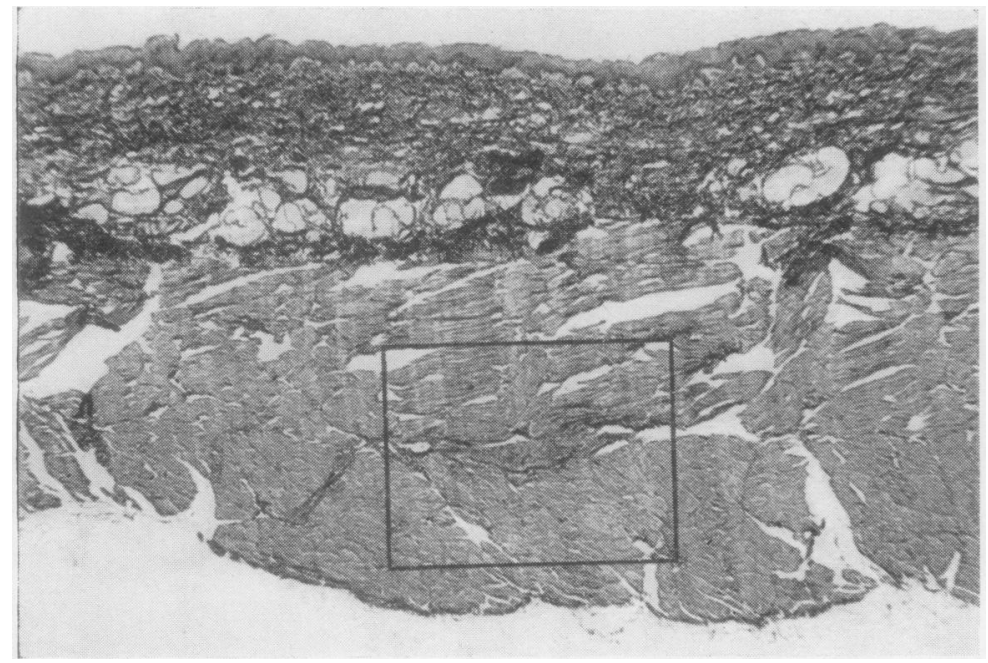

FIG. 5. (a) Section through $\stackrel{\overrightarrow{\vec{\omega}}}{\vec{\omega}}$ middle of oesophagus of nor- $\mathrm{S}$ mal dog. Haematoxylin and $\overrightarrow{\vec{x}}$ eosin. $\times 30$.

FIG. 5. (b) Enlargement centred on Auerbach's plexus. Haematoxylin and eosin. $\times 100$.

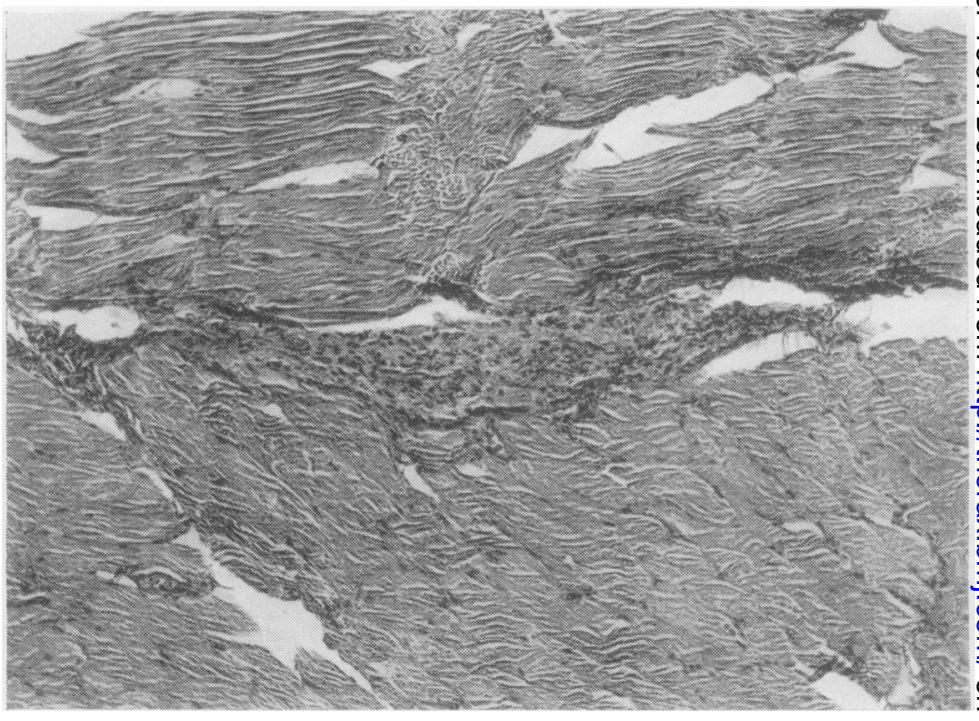

phagus by Stack, Thomson, and Suyama (1957), Knecht and Eaddy (1959), Reed, Archibald, and Cawley (1960), and Morgan and Lumb (1964). They demonstrated a large oesophagus partially filled with food, saliva, and mucus. Ulceration and haemorrhage from the mucosa may be seen. The animal had to be anaesthetized for this procedure, and the oesophagoscope passed easily into the stomach. However, it is to be noted that easy passage of the sphincter with sounds, bougies, or an oesophagoscope is possible whether the animal is anaesthetized or not, so that a stomach tube can be used for intragastric feeding. If the radiographic technique is satisfactory, there appears to be no advantage in performing oeophagoscopy, which carries the risk of anaesthesia with jt.

The typical macroscopic pathology is demon- $N$ strated in this puppy. The oesophagus is converted into a thin-walled atonic sac extending from the diaphragm to the superior sphincter. It is essential ${ }^{\circ}$ at necropsy to reconfirm the easy passage of fluid $\stackrel{\circ}{\square}$ through the lower sphincter and thereby exclude $\$$ any anatomical obstruction.

Histological examination in our case revealed $\frac{0}{\circ}$ normal muscle in the relatively thinned muscle $\overrightarrow{\mathbb{D}}$

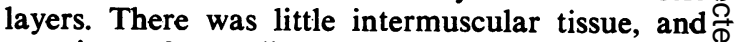

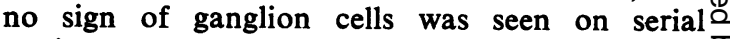
sections. 
T A B L E

REPORTS OF OESOPHAGEAL ACHALASIA IN DOGS

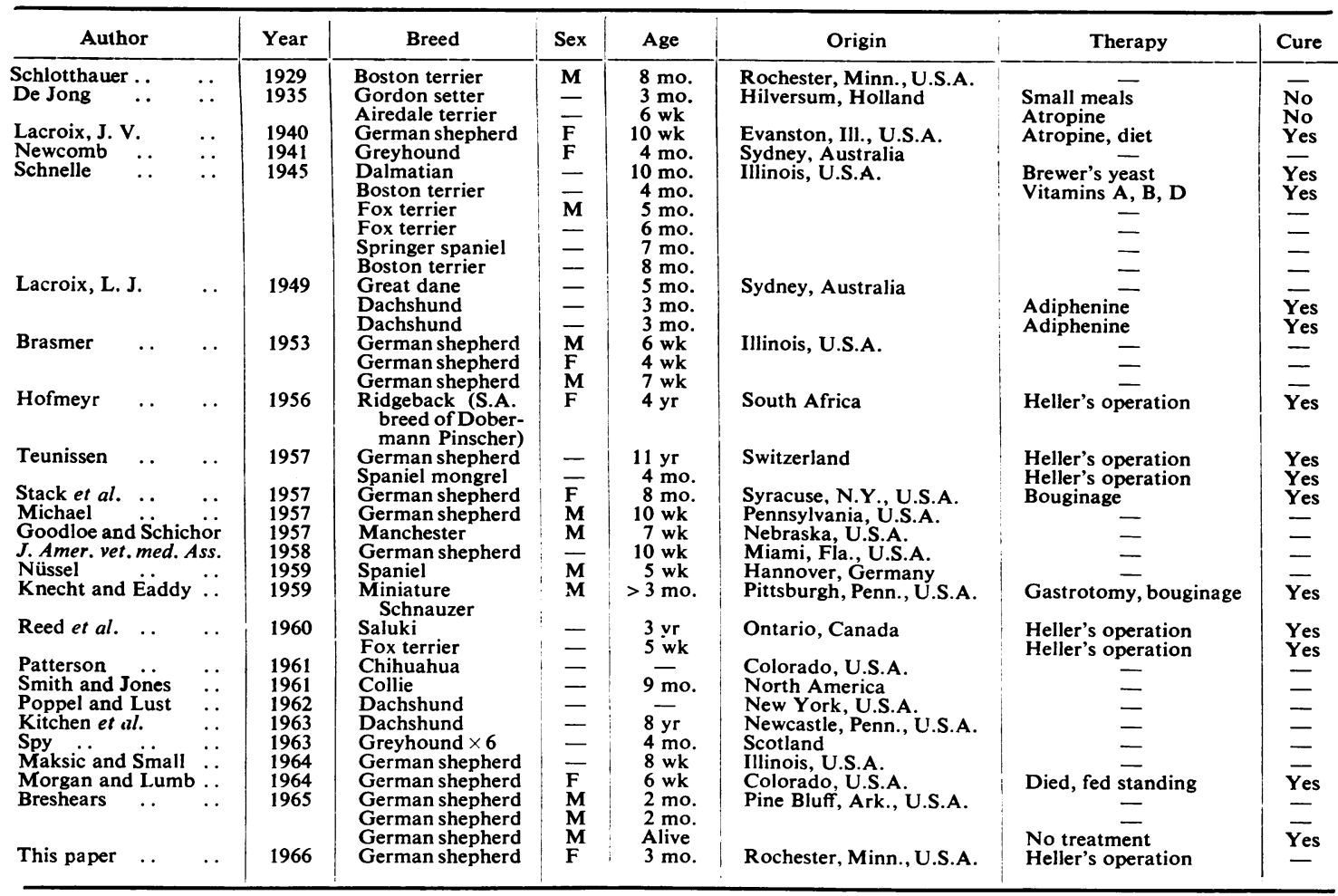

As a result of our own experience we suggest that the best treatment for a dog with achalasia is to feed fluids two or three times each day with the $\operatorname{dog}$ in a vertical position; if this fails, a stomach tube may be passed for intragastric feeding. This would enable the dog to regain its weight and develop immunity to infection. The evidence suggests that this might even enable the animal to pass through the critical stage following weaning, and if, after a few months, no further progress has been made, a modified Heller procedure might be done. If the animal is fit when first seen, it may be possible to proceed with an operation immediately.

Our thanks are due to Dr. and Mrs. J. H. Grindlay for kindly allowing examination of the puppy, its sire, and dam ; to Dr. C. F. Code for help in analysing the motility records and fluoroscopy; and to J. F. Schlegel and Delbert Minske for technical assistance.

This investigation was supported in part by Research Grant AM-5457 from the National Institutes of Health, Public Health Service.

\section{REFERENCES}

Brasmer, T. H. (1953). Congenital esophageal dilatation. North Amer. Vet., $34,36$.

Breshears, D. E. (1965). Esophageal dilatation in six-week-old male German shepherd pups. Vet. Med. (Small Animal Clinician), 60, 1034.

De Jong, J. (1935). Een geval van dilatatio oesophagi bij den hond. T. Diergeneesk., $62,1248$.

Detweiler, D. K., and Allam, M. W. (1955). Persistent right aortic arch with associated esophageal dilatation in dogs. Cornell Vet.,
45,209 .

Djukič, B., and Oreškovił, A. (1959). Dilatation of the oesophagus in a mare. Acta vet. (Beogr.), 9, 95.

Goodloe, L. O., and Schichor, S. A. (1957). Megaesophagus in a pup. J. Amer. vet. med. Ass., 130, 285.

Guarda, F. (1962). Sulla ipertrofia idiopatica dell'esofago degli equini: Contributo casistico ed anatomo-patologico. Ann. Fac Med. vet. Torino, $12,29$.

Hayes, M. H. (1908). Friedberger and Fröhner's Veterinary Pathology, 6 th ed. Hurst and Blackett, London.

Hofmeyr, C. F. B. (1956). Cardioplasty for achalasia in the dog. Vet. Med., 51, i15.

Hutyra, F., Marek, J., and Manninger, R. (1938). Special Pathology and Therapeutics of the Diseases of Domestic Animals, 4th English
ed., ed. J. R. Greig, vol. 2. Baillière, Tindall and Cox, London.

Joest, E. (1926). Handbuch der speziellen pathologischen Anatomie der Haustiere, vol. 1. Schoetz, Berlin.

Kitchen, R. H., Kehler, W. H., and Henthorne, J. C. (1963). Megaesophagus in a dog. J. Amer. vet. med. Ass., 143, 1106.

Knecht, C. D., and Eaddy, J. A. (1959). Canine esophageal achalasia corrected by retrograde dilatation-a case report. Ibid., 135, 554.

Lacroix, J. V. (1940). Cardiospasm in puppy. N. Amer. Vet., 21, 673. Lacroix, L. J. (1949). Congenital dilatation of the esophagus. Ibid.,
30, 29. 
Lawson, D., Penhale, Barbara, and Smith, G. (1957). Persistent right aortic arch in the dog causing oesophageal obstruction. Vet. Rec., 69, 326.

Maksic, D., and Small, E. (1964). Diagnostic radiography of the canine esophagus. Vet. Med., 59, 397.

Michael, S. J. (1957). Megaesophagus in a pup. J. Amer. vet. med. Ass., 130, 284

Milks, H. J., and Williams, W. L. (1935). Persistence of the right instead of the left primitive aorta in the dog, incarcerating the esophagus and causing its dilatation. Cornell Vet., 25, 365.

Morgan, J. P., and Lumb, W. V. (1964). Achalasia of the esophagus in the dog. J. Amer. vet. med. Ass., 144, 722.

Newcomb, J. W. (1941). Dilatation of the oesophagus in a dog. Aust. vet. J., 17, 107.

Nieberle, K., and Cohrs, P. (1931). Lehrbuch der speziellen pathologischen Anatomie der Haustiere. Fischer, Jena.

Nüssel, M. (1959). Ösophagusdilatation beim Hund. Dtsch. tierärtz. Wschr., 66, 263

Patterson, S. A. (1961). Disease conditions in animals, with radiographic findings, that are also present in man. Radiology, 76, 818 .

Poppel, M. H., and Lust, F. J. (1962). Achalasia of the esophagus in a dachshund. Amer. J. Roentgenol., 88, 741.
Reed, J. H., Archibald, J. A., and Cawley, A. J. (1960). Achalasia of the esophagus: The signs of achalasia, alternately known as cardiospasm or mega-esophagus, and the technic for esophago- $\overline{\bar{C}}$. myotomy. Mod. vet. Pract., 41, no. 21 (Nov. 1), p. 32.

Schlegel, J. F., and Code, C. F. (1958). Pressure characteristics of the esophagus and its sphincters in dogs. Amer. J. Physiol., 193, 9.르

Schlotthauer, C. F. (1929). Congenital defect of the stomach of a dog. గ్రు J. Amer. vet. med. Ass., 75, 370.

Schnelle, G. B. (1945). Radiology in Canine Practice, p. 240. The $\overrightarrow{0}$ North American Veterinarian, Evanston, Illinois.

Smith, H. A., and Jones, T. C. (1961). Veterinary Pathology, 2nd ed. Lea and Febiger, Philadelphia.

Spy, G. M. (1963). Megaloesophagus in a litter of greyhounds. Vet. Rec., 75, 853.

Stack, W. F., Thomson, J. D., and Suyama, A. (1957). Achalasia of the esophagus with megaesophagus in a dog. $J$. Amer. vet. med. N

Teunissen, G. H. B. (1957). Thoraxchirurgie beim kleinen Haustier. ir Schweiz. Arch. Tierheilk., 99, 708.

Wejda, E. (1961). Dilatatio et stenosis oesophagi bei einem Fohlen (hervorgerufen durch wandernde Gastrophiluslarven). Mh. Vet.Med., 16, 317. Abstract in Vet. Bull. (Weybridge), 31, 589.

(What is your diagnosis?) (1958). J. Amer. vet. med. Ass. (advert.). 133 (Nov. 15), 39 